\title{
Effect of harvesting technique and presence or absence of corpus luteum on in vitro development after parthenogenetic activation of oocytes recovered from buffalo ovaries
}

\author{
Yelisetti Uma Mahesh ${ }^{1,2}$, Murakonda Mutha Rao ${ }^{1}$, Poda Sudhakar ${ }^{2}$ and Krothapalli Raja Surya Sambasiva Rao ${ }^{2}$ \\ 1. Livestock Research Station, Lam Farm, Sri Venkateswara Veterinary University, Guntur, \\ Andhra Pradesh - 522034, India; 2. Department of Biotechnology, University College, Acharya Nagarjuna University, \\ Nagarjuna Nagar, Guntur, Andhra Pradesh-522510, India. \\ Corresponding author: Yelisetti Uma Mahesh, email: maheshyelisetti@gmail.com, Cell: +91-9849252352 \\ Received: 28-02-2014, Revised: 03-04-2014, Accepted: 09-04-2014, Published online: 15-05-2014
}

doi: 10.14202/vetworld.2014.315-320 How to cite this article: Mahesh YU, Rao MM, Sudhakar P and Rao KRSS (2014) Effect of harvesting technique and presence or absence of corpus luteum on in vitro development after parthenogenetic activation of oocytes recovered from buffalo ovaries, Veterinary World 7(5): 315-320.

\begin{abstract}
Aim: The present study was aimed at assessing the influence of three oocyte harvesting (aspiration, puncture and slicing) methods and presence or absence of corpus luteum (CL) on recovery efficiency and subsequent in vitro maturation and parthenogenetic development of immature oocytes recovered from buffalo ovaries.

Materials and Methods: Buffalo ovaries were collected from local slaughter house and oocytes were collected by using aspiration, puncture and slicing methods. Collected oocytes were matured in vitro in TCM-199 medium supplemented with $10 \%$ fetal bovine serum (FBS), $0.22 \mathrm{mM}$ sodium pyruvate, $10 \mu \mathrm{g} / \mathrm{mL}$ of follicle-stimulating hormone, $6 \mathrm{IU} / \mathrm{mL}$ luteinizing hormone, $1 \mu \mathrm{g} / \mathrm{mL} 17-\beta$ estradiol, $100 \mathrm{IU} / \mathrm{mL}$ penicillin and $0.1 \mathrm{mg} / \mathrm{mL}$ streptomycin. In vitro matured oocytes were activated by ethanol $(7 \%)$ followed by $6-\mathrm{DMAP}(2 \mathrm{mM})$ and cultured to assess the in vitro developmental capacity.

Results: The average total number of oocytes recovered per ovary was significantly $(\mathrm{P}<0.05)$ higher in slicing $(7.88 \pm 0.54)$ than the aspiration $(2.50 \pm 0.11)$ and puncture $(3.59 \pm 0.18)$ methods. The number of culture grade oocytes per ovary was significantly higher in slicing (5.40 \pm 0.29$)$ than in puncture $(2.45 \pm 0.12)$ and aspiration $(1.94 \pm 0.11)$ methods. However, the percentage of culture grade oocytes was higher in the aspiration method $(77.67 \%)$, compared to the puncture $(68.24 \%)$ or slicing $(68.51 \%)$ methods. The oocyte recovery was significantly lower $(\mathrm{P}<0.05)$ in CL containing ovaries than that of ovaries without CL (3.01vs.5.17). However, the presence of CL did not affect the oocytes ability to reach the MII stage (73.07\%vs.75.77\%). The results showed that the rates of Cumulus oocyte complexes (COCs) that reached the metaphase-II (M-II) stage were similar in aspiration, puncture and slicing techniques (77.29, 76.12 and $73.92 \%$ respectively). The oocytes obtained were matured and parthenogenetically activated in vitro using ethanol and 6-DMAP. The oocyte collection methods and presence or absence of CL did not influence the subsequent embryonic developmental competence.
\end{abstract}

Conclusion: It can be concluded that slicing method can be used as an alternative to aspiration and puncture methods to recover oocytes from buffalo ovaries; as slicing method resulted higher oocyte yield and similar in vitro development rate when compared with other methods.

Keywords: aspiration, buffalo, IVM, oocytes, parthenogenetic activation, puncture, slicing.

\section{Introduction}

Growing human population, increasing urbanization and rising per capital income are predicted to double the demand for the supply of livestock products in developing countries over the next two decades [1]. Livestock production is growing faster than any other sub-sector and it is predicted that by 2020, livestock will produce more than half of the total global agricultural output in terms of value [2]. The buffalo occupies an integral part in the livestock economy of Asia as well as of India and India has highest buffalo population in the world [3]. Buffaloes are major contributors for milk, meat and draught power and the buffalo is considered as the animal of the future in India due to their ability to survive in harsh climatic conditions,

Copyright: The authors. This article is an open access article licensed under the terms of the Creative Commons Attribution License (http://creativecommons.org/licenses/by/2.0) which permits unrestricted use, distribution and reproduction in any medium, provided the work is properly cited. in comparison with cattle. However, reproductive efficiency of this species is low and hampered due to delayed puberty, silent estrus, prolonged inter calving intervals, poor conception rates, seasonal anoestrus and poor super ovulatory response [4]. Reproduction lies at the heart of any livestock breeding enterprise and is vital to maintain or increase the number of animals required for production. In order to improve reproductive efficiency of buffalo; assisted reproductive technologies such as artificial insemination (AI), multiple ovulation and embryo transfer (MOET) and in vitro production of embryos has been introduced [4]. Progress in the use of embryo transfer in the buffalo is slow due to poor super ovulatory response. In vitro embryo production (IVEP) would be an effective technique to improve the efficacy of transferable embryo production [5]. However, in vitro embryo production systems in buffalo are still sub optimal when compared with bovine and requires substantial improvement. 
Therefore, it seems that considerable basic developmental work should be undertaken to standardize IVEP techniques. An inherent problem with buffalo reproduction is the poor oocyte yield per ovary, which has been attributed to a low number of primordial follicles present in buffalo ovary [6]. The availability of a sufficient number of oocytes and their quality is the pre-requisite for IVEP procedure such as in vitro maturation (IVM), in vitro fertilization (IVF), transgenic and somatic cell nuclear transfer (SCNT). Oocyte quality is one of the major factors determining the success of in vitro embryo production [7]. The reduced developmental ability of oocytes recovered from the abattoir ovaries limits the suitability of these oocytes for biotechnology research and slows the application of IVEP to commercial embryo transfer [8]. The cumulus cells surrounding the oocyte play an essential role in promoting oocyte maturation, and they are known to supply nutrients, energy substrates [7] and to mediate the positive effects of hormones on the cumulus oocyte complexes (COCs) [9]. Cumulus cell investment is very much dependent on the efficiency of oocyte collection method. Ovaries collected from abattoir animals are the cheapest and the most abundant source of primary oocytes for in vitro production of embryos. Several methods of oocyte recovery including aspiration of follicles, puncture of follicles and slicing of ovaries have been used $[8,10-14]$ to recover high quality oocytes with more number of cumulus cell layers from ovaries collected from slaughtered animals. However, the oocyte yield and quality varies with the harvesting technique employed and depends on the reproductive status of the donor, season, species and breed [15].

The present study was under taken to study the influence of various oocyte collection methods and presence or absence of corpus luteum on in vitro maturation and subsequent embryo development after parthenogenetic activation of oocytes collected from buffalo ovaries.

\section{Materials and Methods}

Experimental design: A total of 334 buffalo ovaries (6 replicates) were obtained from slaughtered house irrespective of season and categorized into 2 groups based on presence $(n=90)$ or absence $(n=144)$ of corpus luteum. To study the efficacy of three harvesting techniques on the oocyte yield and quality and in vitro development, oocytes were collected from individual ovaries by using aspiration, puncture and slicing methods. The total oocyte yield as well as different grades of COCs recovered from each ovary using three harvesting methods was recorded and comparisons were made based on yield and quality of oocytes per ovary. The culture grade oocytes recovered by three methods were in vitro matured and activated to study the effect of three harvesting techniques on in vitro development of oocytes.

Maturation rate of the collected oocytes assessed based on cumulus cell expansion (CCE), extrusion of polar body and ability to reach the TI/MII stage. In vitro development capability was assessed based on cleavage and blastocyst rate after parthenogenetic activation. In vitro maturation and developmental rates were expressed as mean of percentage. To investigate the influence of corpus luteum on the quantity and quality and the developmental competence in vitro, the ovaries were divided into two groups i.e. ovaries with and without corpus luteum (CL) and oocytes were collected separately from each ovary from two groups and cultured in vitro. To study the influence of CL on oocyte yield and quality the data from the collection methods were pooled and analyzed.

Preparation of media: All chemicals and media were purchased from Sigma Chemical Co. (St. Louis, MO, USA) and plastic ware from Nunc, Denmark, unless otherwise indicated. HEPES-buffered tissue culture medium 199 (M199) supplemented with 10\% FBS, penicillin $(100 \mathrm{IU} / \mathrm{mL})$ and streptomycin $(0.1 \mathrm{mg} / \mathrm{mL})$ was used for washing and handling of COCs. IVM of oocytes was carried out using IVM medium that consisted of bicarbonate-buffered tissue culture medium 199 supplemented with $10 \%$ FBS, $0.22 \mathrm{mM}$ sodium pyruvate, $10 \mu \mathrm{g} / \mathrm{mL}$ of follicle-stimulating hormone, 6 $\mathrm{IU} / \mathrm{mL}$ luteinizing hormone, $1 \mu \mathrm{g} / \mathrm{mL} 17-\beta$ estradiol, $100 \mathrm{IU} / \mathrm{mL}$ penicillin and $0.1 \mathrm{mg} / \mathrm{mL}$ streptomycin. All media were sterilized by filtration through $0.22 \mu \mathrm{m}$ filter (Millipore, Billerica, MA, USA) and equilibrated in a humidified atmosphere with 5\% carbon dioxide at $38.5 \mathrm{C}$ for at least $2 \mathrm{~h}$ prior to use.

Oocyte collection and classification: Buffalo ovaries were obtained from a local slaughter house and were transported in a flask containing $0.9 \%$ normal saline at room temperature within $2 \mathrm{~h}$ to the laboratory. Each ovary was then examined for the presence of visible follicles and corpora lutea. Ovaries were rinsed once in $70 \%$ alcohol and thrice in pre-warmed D-PBS. The ovaries were then placed in oocyte collection medium (D-PBS, Gibco-BRL, USA) supplemented with $0.4 \%$ BSA, gentamycin sulphate $50 \mu \mathrm{g} / \mathrm{ml}$ and $10 \mathrm{IU} / \mathrm{ml}$ heparin). Each ovary was processed individually and oocytes were collected by one of the following methods.

Aspiration method: visible follicles (2-6 mm diameter) on the ovaries were aspirated through a 18 gauze needle attached to sterile plastic syringe containing $2 \mathrm{ml}$ oocyte collection medium (OCM). Aspirated follicular fluid was then transferred to a sterile $35 \mathrm{~mm}$ Petri-dish.

Puncture method: the whole ovarian surface was punctured by a sterile 18 gauze hypodermic needle while the ovary is held completely sub merged in OCM in a $30 \mathrm{~mm}$ Petri-dish. In slicing method: a hemostat was attached to the base of the ovary to hold it firmly in place and 2-3 mm deep incisions were made across the whole ovarian surface using sterile scalpel blade. The ovary was swirled vigorously in Petri-dish containing OCM. The Petri-dish was kept undisturbed for $5 \mathrm{~min}$ to allow the COCs to settle. The oocytes were separated 
Table-1: Effect of different harvesting techniques and presence or absence of corpus luteum on the quantity and quality of oocytes recovered from buffalo ovaries.

\begin{tabular}{|c|c|c|c|c|c|c|}
\hline \multirow[t]{2}{*}{ Attributes } & \multirow{2}{*}{$\begin{array}{c}\text { Total number } \\
\text { of oocytes }\end{array}$} & \multicolumn{4}{|c|}{ Oocytes per ovary (Mean $\pm \mathrm{SE})^{*}$} & \multirow[b]{2}{*}{$\begin{array}{c}\text { Culture grade } \\
\text { (Good + Fair) (\%) }\end{array}$} \\
\hline & & Total & Good (\%) & Fair (\%) & Poor (\%) & \\
\hline \multicolumn{7}{|c|}{ Harvesting technique } \\
\hline Aspiration $(n=120)$ & 300 & $2.50 \pm 0.11^{\mathrm{a}}$ & $1.07 \pm 0.06^{a}(43.00)$ & $0.87 \pm 0.06^{\mathrm{a}}(34.67)$ & $0.56 \pm 0.05^{\mathrm{a}}(22.33)$ & $1.94 \pm 0.11^{\mathrm{a}}(77.67)$ \\
\hline Puncture $(n=106)$ & 381 & $3.59 \pm 0.18^{b}$ & $1.52 \pm 0.11^{b}(42.26)$ & $0.93 \pm 0.06^{\mathrm{a}}(24.79)$ & $1.14 \pm 0.09^{b}(31.76)$ & $2.45 \pm 0.12^{a}(68.24)$ \\
\hline $\begin{array}{l}\text { Slicing }(n=108) \\
\text { Overall }(n=334) \\
\text { Presence or absenc }\end{array}$ & $\begin{array}{c}851 \\
1532 \\
\text { ce of } C L\end{array}$ & $\begin{array}{l}7.88 \pm 0.54^{\circ} \\
4.58 \pm 0.20\end{array}$ & $\begin{array}{c}3.38 \pm 0.19^{c}(42.89) \\
1.96 \pm 0.09(42.75)\end{array}$ & $\begin{array}{c}2.02 \pm 0.15^{\mathrm{b}}(27.50) \\
1.26 \pm 0.06(27.48)\end{array}$ & $\begin{array}{l}2.48 \pm 0.17^{c}(31.49) \\
1.36 \pm 0.20(29.77)\end{array}$ & $\begin{array}{c}5.40 \pm 0.29^{b}(68.51) \\
3.22 \pm 0.14(70.23)\end{array}$ \\
\hline With $C L(n=90)$ & 271 & $3.01 \pm 0.20^{\mathrm{a}}$ & $1.40 \pm 0.11^{\mathrm{a}}(46.49)$ & $0.78 \pm 0.08^{\mathrm{a}}(25.83)$ & $0.83 \pm 0.08^{\mathrm{a}}(27.68)$ & $2.18 \pm 0.17^{\mathrm{a}}(72.32)$ \\
\hline Without CL $(n=244)$ & 1261 & $5.17 \pm 0.25^{b}$ & $2.17 \pm 0.11^{b}(41.95)$ & $1.44 \pm 0.08^{b}(27.83)$ & $1.56 \pm 0.10^{b}(30.21)$ & $3.61 \pm 0.17^{\mathrm{b}}(69.78)$ \\
\hline
\end{tabular}

Mean values in the same column with different superscripts differ significantly at $p<0.05$

into a $35 \mathrm{~mm}$ Petri-dish for grading at $63 \mathrm{x}$ magnification and then graded as good, fair and poor quality based on their cumulus cell investment, compactness and homogeneity of ooplasm [8]. The number and quality of oocytes were recorded for each ovary.

In vitro maturation of cumulus oocyte complexes: After isolation and classification of COCs, good and fair quality COCs was selected for IVM. All COCs were washed extensively in fresh droplets of handling medium followed by IVM medium. The washed oocytes were finally transferred into a 4-well plate containing $600 \mu \mathrm{L}$ of pre-equilibrated IVM medium. The medium was overlaid with equilibrated mineral oil and cultured in an incubator with $5 \% \mathrm{CO}_{2}$ under humidified air at $38.5^{\circ} \mathrm{C}$ for $24 \mathrm{~h}$.

Evaluation of oocytes following IVM: At the end of maturation period, COCs were examined for cumulus cell expansion (CCE) and the oocytes were denuded by treating them with hyaluronidase $(100 \mathrm{IU} / \mathrm{mL})$ for 10 min and by repeatedly passing through a fire polished narrow bore glass pipette and then examined for extrusion of the $1^{\text {st }}$ polar body (PB) and those oocytes not extruded $1^{\text {st }} \mathrm{PB}$ were evaluated for nuclear status according to method used by Otoi et al. [16]. Briefly, denuded oocytes were fixed and permeabilized for 15 min at room temperature in D-PBS supplemented with $3.7 \%$ paraformaldehyde and $1 \%$ Triton-X100, and then placed in D-PBS containing $0.3 \%$ polyvinylpyrrolidone for $15 \mathrm{~min}$ at room temperature. The oocytes were subsequently transferred into a small drop of DPBS supplemented with $90 \%$ glycerol and $10 \mu \mathrm{g} / \mathrm{ml}$ bis-benzimide (Hoechst 33342) on a glass slide, covered with a cover slip supported by four droplets of vaseline and paraffin mixture (3:1) and incubated overnight at $4{ }^{\circ} \mathrm{C}$. The oocytes were then examined using a fluorescence microscope (Axioplan, Carl Zeiss, Germany) and classified according to chromatin configuration as germinal vesicle $(\mathrm{GV})$, germinal vesicle break down (GVBD), metaphase-I (MI), telophase-I (TI), and metaphase-II (MII). Those with diffusely stained cytoplasm characteristic of non-viable cells and those in which the chromatin was unidentifiable or not visible, were considered as degenerated. Meiotic maturation was defined as the number of oocytes that extruded a 1st PB and matured to the TI/MII stage relative to the total number of oocytes that were cultured in vitro. Oocytes that were arrested at the GV, GVBD stage or only progressed to MI were considered as immature.

Activation of oocytes: The oocytes that cultured in vitro for $24 \mathrm{~h}$ and having $1^{\text {st }} \mathrm{PB}$ were activated using a combination of $7 \%$ ethanol for $5 \mathrm{~min}$ and $2 \mathrm{mM} 6-$ dimethylaminopurine (6-DMAP) for $4 \mathrm{~h}$ in $\mathrm{mSOF}$ medium (Millipore, USA). Following six washes in $\mathrm{mSOF}$ medium oocytes were incubated in $\mathrm{mSOF}$ medium in a humidified atmosphere of $5 \% \mathrm{CO}_{2}$ incubator at $38.5^{\circ} \mathrm{C}$ for 7 days for further development.

Statistical analysis: Oocyte recovery rates using different collection techniques were analyzed by analysis of variance (ANOVA) and effect of presence or absence of CL on oocyte recovery was analyzed using Student's t-test. For in vitro maturation, the percentage data were arcsine transformed and analyzed by ANOVA and followed by a least square difference (LSD) test using SPSS software version 16.0 (SPSS Inc, Chicago, IL, USA). Differences in means were considered significant at $\mathrm{p}<0.05$.

\section{Results}

Effect of collection method on oocyte recovery and in vitro development: The mean of total oocyte recovery in the present study was 4.58 of which $1.96(42.75 \%)$, $1.26(27.48 \%), 1.36(29.77 \%)$ and $3.22(70.23 \%)$ were of good, fair, poor and culture grade oocytes, respectively (Table-1). The mean number of oocytes recovered per ovary by slicing (7.88) was significantly higher $(\mathrm{p}<0.05)$ than that achieved by follicle puncture (3.59) or aspiration (2.50) methods (Table-1). The number of pooled culture grade (good and fair) oocytes per ovary was high in slicing (5.40) than follicle puncture (2.45) or aspiration (1.94) methods. There was a significant increase in number of morphologically poor quality oocytes in the slicing (2.48) method than in the puncture (1.14) and aspiration (0.56) groups. However, the proportion of culture grade oocytes was higher in aspiration method (77.67\%) than in puncture $(68.24 \%)$ and slicing $(68.51 \%)$ methods and poor oocyte recovery was lowest in aspiration than puncture 
Table-2: Effect of different collection methods and presence or absence of corpus luteum (CL) on in vitro maturation and development of buffalo oocytes.

\begin{tabular}{|c|c|c|c|c|c|}
\hline \multirow[t]{2}{*}{ Attributes } & \multicolumn{3}{|c|}{ Harvesting technique $(\% \text { mean } \pm \mathrm{SE})^{*}$} & \multicolumn{2}{|c|}{$\begin{array}{c}C L \text { presence or absence } \\
(\% \text { mean } \pm \mathrm{SE})^{*}\end{array}$} \\
\hline & Aspiration & Puncture & Slicing & With CL & Without CL \\
\hline \multicolumn{6}{|l|}{ In vitro maturation } \\
\hline Number of oocyte cultured & 190 & 197 & 202 & 133 & 137 \\
\hline Number of oocytes showed CCE & $96.53 \pm 1.12^{a}$ & $96.36 \pm 1.30^{\mathrm{a}}$ & $96.43 \pm 1.16^{\mathrm{a}}$ & $91.59 \pm 1.21^{\mathrm{a}}$ & $93.07 \pm 1.09^{\mathrm{a}}$ \\
\hline Number of oocyte with PB & $61.24 \pm 1.45^{\mathrm{a}}$ & $61.03 \pm 1.60^{\mathrm{a}}$ & $59.50 \pm 0.62^{\mathrm{a}}$ & $57.48 \pm 0.98^{\mathrm{a}}$ & $62.78 \pm 1.52^{\mathrm{a}}$ \\
\hline Number of oocyte at GV & $0.00 \pm 0.00^{\mathrm{a}}$ & $1.68 \pm 1.07^{\mathrm{a}}$ & $3.01 \pm 1.44^{\mathrm{a}}$ & $3.07 \pm 1.52^{\mathrm{a}}$ & $1.60 \pm 1.01^{\mathrm{a}}$ \\
\hline Number of oocytes at GVBD & $3.64 \pm 1.25^{\mathrm{a}}$ & $3.83 \pm 1.42^{\mathrm{a}}$ & $3.92 \pm 1.33^{\mathrm{a}}$ & $4.51 \pm 1.03^{\mathrm{a}}$ & $2.58 \pm 1.16^{\mathrm{a}}$ \\
\hline Number of oocytes at MI & $18.18 \pm 1.19^{a}$ & $16.88 \pm 1.57^{\mathrm{a}}$ & $15.99 \pm 2.47^{\mathrm{a}}$ & $13.55 \pm 2.34^{\mathrm{a}}$ & $17.27 \pm 1.82^{\mathrm{a}}$ \\
\hline Number of oocytes at TI/MII & $77.29 \pm 0.60^{\mathrm{a}}$ & $76.12 \pm 1.02^{\mathrm{a}}$ & $73.92 \pm 1.73^{\mathrm{a}}$ & $73.07 \pm 0.68^{\mathrm{a}}$ & $75.77 \pm 0.75^{a}$ \\
\hline $\begin{array}{l}\text { Number of oocytes fragmented } \\
\text { In vitro development }\end{array}$ & $0.88 \pm 0.88^{\mathrm{a}}$ & $1.49 \pm 0.94^{\mathrm{a}}$ & $3.15 \pm 1.00^{\mathrm{a}}$ & $5.79 \pm 1.91^{\mathrm{a}}$ & $2.78 \pm 1.24^{\mathrm{a}}$ \\
\hline Number of oocytes activated & 91 & 98 & 122 & 58 & 66 \\
\hline Number of oocytes cleaved & $63.62 \pm 5.80^{\mathrm{a}}$ & $57.80 \pm 2.72^{\mathrm{a}}$ & $57.39 \pm 1.87^{\mathrm{a}}$ & $58.92 \pm 2.18^{\mathrm{a}}$ & $63.60 \pm 0.24^{\mathrm{a}}$ \\
\hline Number of oocytes reached to BL & $15.44 \pm 0.38^{\mathrm{a}}$ & $14.50 \pm 1.00^{\mathrm{a}}$ & $13.16 \pm 1.11^{\mathrm{a}}$ & $13.80 \pm 1.60^{\mathrm{a}}$ & $15.14 \pm 0.75^{a}$ \\
\hline
\end{tabular}

Mean values in the same column with different superscripts differ significantly at $\mathrm{p}<0.05$

and slicing method.

The results of IVM using culture grade COCs collected by three methods were summarized in Table2. The CCE and extrusion of polar body rate was similar among three oocyte collection methods. There was no statistically significant difference in the proportion of MII oocytes after IVM of culture grade COCs harvested by three methods, although a slightly lower percentage of MII oocytes were found in COCs obtained by slicing $(73.92 \%)$ than those obtained by aspiration and puncture $(77.29$ and $76.12 \%$, respectively) methods. The cleavage and blastocyst rates were similar in aspiration (63.62 and 15.44\%), puncture (57.80 and $14.50 \%)$ and slicing (57.39 and $13.16 \%$ ) methods.

Influence of presence or absence of corpus luteum on yield and in vitro development of immature oocytes: The presence of CL on ovary adversely affected the total oocyte yield when compared with ovaries without $\mathrm{CL}$ in aspiration (1.87 vs. 2.80 ), puncture (2.54 vs. 3.87 ) and slicing (4.90 vs. 8.97 ) methods. The average number of culture grade (good and fair quality) COCs collected by aspiration, puncture and slicing methods in CL containing ovary were $1.46,1.68$ and 3.52 respectively and $2.17,2.65$ and 6.09 respectively in ovary without CL. To study the influence of CL the data from three methods were combined and revealed that non-luteal phase (without CL) ovaries yield significantly $(\mathrm{p}<0.05)$ higher number of oocytes when compared to luteal phase (With CL) ovaries (Table-1). However, the proportions of different quality of oocytes were similar in between ovaries with or without CL. Although the effect of presence or absence of CL was reflected in number of oocytes recovered, no significant difference $(p>0.05)$ was observed in CCE of COCs in between luteal ovaries $(91.59 \pm 1.21)$ and non-luteal ovaries $(93.07 \pm 1.09)$. The ability to reach MII stage was similar in oocytes collected from with or without CL. However, a slight decrease in MII stage and $\mathrm{PB}$ were observed in oocytes recovered from the
CL containing ovaries than those of ovaries without CL (Table-2). The proportion of fragmented oocytes was increased in oocytes collected from ovaries with CL (5.79\%) than that of without CL $(2.78 \%)$. There was no significant difference in cleavage and blastocyst development rate in between these two groups.

\section{Discussion}

Several techniques were used for the collection of oocytes from the ovaries of domestic animals such as buffalo [13, 17], cattle [12], goats [8, 11, 18] and sheep [19]. The most common techniques used are the aspiration of visible ovarian follicles [13, 19], slicing of the ovary [8] or follicular puncture [19]. The mean oocyte recovery (4.58) in present study was higher than the 0.73 reported by Totey et al. [20]; 3.41 reported by Gupta et al. [21], 2.31 reported by Jamil et al. [13], and similar to 4.60 reported by Rao and Mahesh [17] and 5.7 reported by Prabhakar et al. [22]. However, the mean oocyte recovery in buffaloes was lower when compared with cattle [12]. This difference may be attributed to the considerably low primordial follicle reserves in buffalo ovaries than in cattle [23]. Further, the mean number of culture grade oocytes (3.22) recovered per ovary in present study was higher than the earlier reports $[13,24]$. In present study, slicing yielded significantly $(\mathrm{P}<0.05)$ higher number of oocytes per ovary, than the aspiration and puncture methods. These findings were in agreement with the earlier reports in buffalo [13, 14, 22]. In accordance with the results of the present study, Das et al. [10] reported that slicing (5.7) yielded significantly more oocytes per ovary than follicle puncture (2.6) or aspiration (1.7) and culture grade oocytes (good and fair) were recovered per ovary by slicing (2.6) was higher than by puncture (1.3) or aspiration (0.9). In present study, the proportion of culture grade oocytes (77.67\%) was higher in aspiration method than that of puncture and slicing methods (68.24 and 68.51\% respectively). Moreover, slicing and puncture techniques 
produce more debris and required more washings when compared to aspiration method. As a result, a number of COCs were denuded from cumulus cells due to repeated washing and ultimately resulted in a lower number of normal COCs [18] when compared to aspiration. Furthermore, it is known that the number of oocytes recovery depends on the species, age, season and reproductive status of the donor animal [25].

The culture grade (good and fair quality) oocytes obtained by each method was kept for IVM/IVC procedure, and the CCE, PB and ability to reaching MII stage was similar in between three collection methods. Our results are in agreement to the earlier reports in goat [18], and cattle [12], who found no significant difference in the maturation rate of oocytes collected by different collection methods. In contrast to our findings Mehmood et al. [14] reported that the CCE and MII stage was significantly lower in slicing $(63.3$ and $40.0 \%$ ) than aspiration (86.4 and 65.0\%) respectively. Similarly, El-Gaafary et al. [26] reported that the maturation rate in buffalo oocytes was higher in oocytes obtained from aspiration than oocytes obtained from dissection. Wang et al. [11] reported the maturation rate of 84.0 and $68.4 \%$ of oocytes in goats collected by puncture and slicing technique, which was in close agreement with our results. Furthermore, in present study the maturation rate was not-significantly lower in slicing method than other two methods. The lower maturation rate may be due to more pre-antral oocytes collected by slicing method than by puncture as preantral oocytes have low maturation rate compared with antral oocytes [15]. In present study, different collection methods had the similar cleavage rate and blastocyst yield of the embryos after parthenogenetic activation of the IVM oocytes. These findings were in agreement with the reports of Wang et al. [11] where they reported $13.3,13.5$ and $13.8 \%$ blastocyst rate in goat IVM oocytes collected by aspiration, puncture and slicing techniques respectively and in contrast to finding of Zeinoaldini et al. [27], where they reported significantly higher blastocyst rate oocytes collected by puncture $(19.1 \%)$ and slicing (20.1\%) method than aspiration $(17.8 \%)$ method. The cleavage and blastocyst rate was similar in cattle oocytes collected by three methods [12].

In this study, the presence of a CL significantly (P $<0.05)$ reduced the recovery rate as well as the quality of the oocytes and in agreement with the earlier reports in buffalo [10, 13, 28, 29], and in sheep [19]. The cause of a low number of oocytes per ovary with a CL is likely because of the follicular development is restricted as lutein cells occupy a great portion of the ovary and also attributed that CL may inhibits the growth of follicles and increases their atresia [30]. Hafez [30] reported that progesterone secreted by the luteal cells of the CL inhibited estrus and gave the negative feedback on the anterior pituitary to secret follicle stimulating hormone (FSH). As a result, the growing follicles regressed and became atretic and lead to lower oocyte recovery from
CL containing ovaries. However, oocyte yield per ovary was higher for ovaries with a CL than without a CL in bovine [33] and buffalo [34]. Further, Gupta et al. [21] and El-Naby et al. [33] reported that the oocyte yield per ovary was similar for ovaries with and without CL in buffaloes. The reason could be that the regressing/regressed CL is likely to produce low level of progesterone and it may not be sufficient to inhibit growing follicles in the ovary [34].

Although the influence of presence or absence of CL was reflected in mean number of oocytes collected, no significant difference was observed in maturation rates of oocytes recovered from ovaries with and without CL. These finding were in agreement with the reports of Singh et al. [28] in buffalo, Vajta et al. [35] in cattle indicating that presence of CL and pregnancy does not affect the meiotic competence of oocytes. However, our findings were in contrary to reports of Tasripoo and Kamonpatana, [36] and El-Naby et al. [33] where they recorded higher maturation rate of oocytes recovered from CL containing ovaries. Further, after parthenogenetic activation of IVM oocytes the cleavage and blastocyst rate was similar in between oocyte recovered from ovaries with or without $\mathrm{CL}$ and these findings were in agreement with the earlier reports in goat [8].

\section{Conclusion}

Present study focused on influence of three oocyte collection methods and presence or absence of CL on quantity, quality and developmental ability of oocyte collected from buffalo ovaries. We concluded that the recovery of oocytes using the slicing technique yielded more oocytes per ovary than aspiration and puncture methods. The rate of nuclear maturation of the oocytes was not affected by these different oocytes collection methods. The oocytes collection methods also showed no influence subsequent embryonic developmental competence after parhenogenetic activation using MII stage oocytes. Presence of CL significantly reduced the oocyte yield, however not affected the oocyte in vitro development. Hence, slicing method can be used as an alternative to aspiration or puncture method for harvesting of oocytes from buffalo ovaries.

\section{Authors' contributions}

YUM, MMR and KRSSR designed the study and analyzed the data. YUM and PS carried out the experiments. All authors participated in draft and revision of the manuscript. All authors read and approved the final manuscript.

\section{Acknowledgements}

The authors are thankful to the Principal Scientist, Lam Farm for providing necessary facilities to carry out the research work. The authors are thankful to the Department of Biotechnology, Government of India for financial support. 


\section{Competing interests}

The authors declare that they have no competing interests.

\section{References}

1. Delgado, C., Rosegrant, M., Steinfield, H., Ehui, S. and Courbois C. (1999) Livestock to 2020: The next food revolution. Food, Agriculture and Environment Discussion. International Food policy research institute, Washington D.C., USA. Food and agriculture organization, Rome, Italy and International Livestock Research Institute, Addis Ababa, Ethiopia.p28.

2. Ingawale, M.V., Bakshi, S.A., Birade, H.S., Chinchkar, S.R. and Gulavane, S.U. (2012) Studies on follicular development in Murrah buffaloes with retention of the placenta. Buffalo Bulletin, 31: 193-201.

3. Jain, A., Jai, T., Yathish, H.M., Sachjdeva, G.K., Datta, T.K., De, S., Goswami, S.L. and Patel, R.K. (2011) Headway in reproductive biotechniques for genetic improvement of buffaloes. Curr. Trends. Biotechnol. Pharm., 5: 1206-1232.

4. Nandi, S., Raghu, H.M., Ravindranatha, B.M. and Chauhan, M.S. (2002) Production of buffalo (Bubalus bubalis) embryos in vitro: premises and promises. Reprod. Domest. Anim., 37: 65-74.

5. Drost, M. (2007) Advanced reproductive technology in the water buffalo. Theriogenology, 68: 450-453.

6. Agrawal, S.K. and Tommer, O.S. (1998) Reproductive technologies in Buffalo. Indian Veterinary Research Institute, Izatnagar, Bareilly, UP, India. p37.

7. Krisher, R.L. (2004) The effect of oocyte quality on development. J. Anim. Sci., 82: E14-23.

8. Mahesh, Y.U., Rao, M.M. and Rao, K.R.S.S. (2013) Effect of harvesting technique on recovery rate and in vitro development of caprine follicular oocytes for in vitro procedures. Indian J. Anim. Sci., 83: 56-61.

9. Zuelke, K.A. and Brackett, B.G. (1990) Luteinizing hormone enhanced in vitro maturation of bovine oocytes with and without protein supplementation. Biol. Reprod., 43: 784-787.

10. Das, G.K., Jain, G.C., Solanki, V.S. and Tripathi, V.N. (1996) Efficacy of various collection methods for oocyte retrieval in buffalo. Theriogenology, 46: 1403-1411.

11. Wang, Z.G., Xu, Z.R. and Yu, S.D. (2007a) Effects of oocyte collection techniques and maturation media on in vitro maturation and subsequent embryo development in Boer goat. Czech. J.Anim. Sci., 52:21-25.

12. Wang, Z.G., Yu, S.D. and Xu, S.R. (2007b) Effects of collection methods on recovery efficiency, maturation rate and subsequent embryonic developmental competence of oocytes in Holstein cow. Asian. Australas. J. Anim. Sci., 20: 496-500.

13. Jamil, H., Samad, A., Qureshi, Z.I., Rehman, N.U. and Lodhi, L.A. (2008) Harvesting and evaluation of riverine buffalo follicular oocytes. Turk. J. Vet. Anim. Sci., 32:25-30.

14. Mehmood, A., Anwar, M., Andrabi, S.M.H., Afzal, M. and Naqvi, S.M.S. (2011) In vitro maturation and fertilization of buffalo oocytes: the effect of recovery and maturation methods. Turk. J. Vet. Anim. Sci., 35: 381-386.

15. Izquierdo, D., Villamediana, P., Lopez Bejar, M. and Paramio, M.T. (2002) Effect of in vitro and in vivo culture on embryo development from prepubertal goat IVM- IVF oocytes. Theriogenology, 57: 1431-1441.

16. Otoi, T., Willingham, L., Shin, T., Kraemer, D.C. and Westhusin, M. (2002) Effects of oocyte culture density on meiotic competence of canine oocytes. Reproduction, 124: 775-781.

17. Rao, M.M. and Mahesh, Y.U. (2012) Efficacy of different harvesting techniques on oocyte retrieval from buffalo ovaries. Buffalo Bulletin, 31: 209-213.

18. Hoque, S.A.M., Kabiraj, S.K., Khandoker, M.A.M.Y.,
Mondal, A. and Tareq, K.M.A. (2011) Effect of collection techniques on cumulus oocyte complexes (COCs) recovery, in vitro maturation and fertilization of goat oocytes. Afr. $J$. Biotechnol., 10:9177-9181.

19. Wani, N.A., Wani, G.M., Khan, M.Z. and Sidiqi, M.A. (1999) Effect of different factors on the recovery rate of oocytes for in vitro maturation and in vitro fertilization procedures in sheep. Small. Rumin. Res., 34: 71-76.

20. Totey, S.M., Singh, G., Taneja, M., Pawshe, C.H. and Talwer, G.P. (1992) In vitro maturation, fertilization and development of follicular oocytes from buffalo (Bubalus bubalis). J. Reprod. Fertil., 95: 597-607.

21. Gupta, P.S.P., Nandi, S., Raghu, H.M., Ravindranatha, B.M. and Sarma, P.V. (2003) Oocyte recovery rates in relation to morphology and weight of the ovaries in buffaloes. Indian. $J$. Anim. Res., 37: 147-148.

22. Prabhakar, L., Raju, K.G.S., Rao, K. and Rao, K.S. (2012) Retrieval of oocytes from ovaries of buffalo cows slaughtered in abattoir. Theriogenology insight, 2: 187-195.

23. Danell, B. (1987) Oestrous behavior, ovarian morphology and cyclical variation in follicular system and endocrine pattern in water buffalo heifers. Ph.D. Thesis, Swedish University of Agricultural Sciences, Uppsala, Sweden. p124.

24. Samad, H., Khan, I., Rehman, N. and Ahmad N. (1998) The recovery, in vitro maturation and fertilization of Nili- Ravi buffalo follicular oocytes. Asian. Aust. J. Anim. Sci., 11: 491497.

25. Hussain, R., Nematullah. and Akhter, S. (2005) Effect of season on average number of culturable oocytes recovered from cattle and buffalo ovaries. Pakistan. J. Zool., 37:281-283.

26. El-Gaafary, M.N. and Abdel-Ghaffar, A.E. (1994) In vitro oocytes maturation, fertilization and cleavage in Egyptian buffaloes. Annals. Agric. Sci. Moshtohor. Egypt., 32: 1801-1810.

27. Zeinoaldini, S., Jafari, Z., Sarmast, F., Torbati, E. and Davachi, N.D. (2013) Different harvesting techniques used in ovine in vitro embryo production. Scimetr, 1: e11638.

28. Singh, S., Dhanda, O.P. and Malik, R.K. Effect of the presence of corpus luteum on oocyte recovery and subsequent in vitro maturation and fertilization in buffaloes. Asian. Australas. J. Anim. Sci., 14: 1675-1677.

29. Sahoo, L. and Singla, S.K. (2013) Effect of corpus luteum: quality and recovery of buffalo (Bubalus bubalis) oocytes. Turk. J. Vet. Anim. Sci., 37: 468-471.

30. Hafez, E.S.E. (1993) Folliculogenesis, egg maturation and ovulation. In: Reproduction in Farm Animals, vol. 1. Lea and Febiger, Philadelphia. p114-143.

31. Varisanga, M.D., Sumantri, C., Murakami, M., Fahrudin, M. and Suzuki T. (1998) Morphological classification of the ovaries in relation to the subsequent oocyte quality for IVF produced bovine embryos. Theriogenology, 50: 1015-1023.

32. Abdoon, A.S.S. and Kandil, O.M. (2001) Factors affecting number of surface ovarian follicles and oocytes yield and quality in Egyptian buffaloes. Reprod. Nutri. Dev., 41:71-77.

33. El-Naby, A.A.H.H., Mahmoud, H.K.G.M., Ahmed, Y.F., Abouel-Roos, M.E.A. and Abdel- Ghaffar, A.E. (2013) Effect of season of the year and ovarian structures on oocytes recovery rate, quality and meiotic competence in Egyptian buffaloes. Global Veterinaria, 10: 408-412.

34. Rao, B.S., Mahesh, Y.U., Lakshmikantan, U.R., Suman, K., Charan, K.V. and Shivaji, S. (2010) Developmental competence of oocytes recovered from postmortem ovaries of the endangered Indian Blackbuck (Antilope cervicapra). J. Reprod. Dev., 56: 623-629.

35. Vajta, G., Machaty, Z., Barrandi, Z.S. and Varga, Z.S. (1992) Embryos derived from the in vitro fertilization of pregnant cows. Theriogenology, 37: 811-815.

36. Tasripoo, K. and Kamonpatana, M. (1997) Assessment of factors contributing to in vitro maturation, fertilization and cleavage rate of swamp buffalo oocytes. Buffalo J, 3: 325336. 